\title{
Genotype-Phenotype Correlation in a MODY 2 Family: An Under-Diagnosed Disease
}

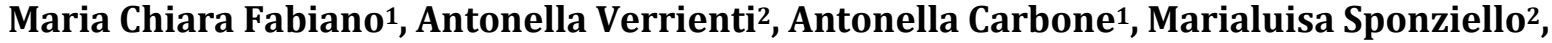 Pasquale Bellitti', Rocco Bruno ${ }^{1}$}

${ }^{1}$ Department of Medicine, Unit of Endocrinology, Tinchi-Pisticci Hospital, Matera, Italy

${ }^{2}$ Department of Internal Medicine and Medical Specialisties, University of Rome "Sapienza”, Roma, Italy

Email: roccobruno1@virgilio.it

How to cite this paper: Fabiano, M.C., Verrienti, A., Carbone, A., Sponziello, M., Bellitti, P. and Bruno, R. (2016) GenotypePhenotype Correlation in a MODY 2 Family: An Under-Diagnosed Disease. Journal of Diabetes Mellitus, 6, 263-268. http://dx.doi.org/10.4236/jdm.2016.64027

Received: June 28, 2016

Accepted: October 16, 2016

Published: October 19, 2016

Copyright $\odot 2016$ by authors and Scientific Research Publishing Inc. This work is licensed under the Creative Commons Attribution International License (CC BY 4.0).

http://creativecommons.org/licenses/by/4.0/

\begin{abstract}
Objective: We report a case of a MODY 2 family: a disease frequently under-diagnosed. Patients and Methods: We analyzed the case of three brothers that we suspected as affected by Type 1 diabetes because of their low BMI without clinical or biochemical parameters for this diagnosis. Their father was diagnosed as affected from Type 2 diabetes at the age 31 years old. Results: Genetic analysis revealed the presence in all analyzed family members of non-sense Ser 383x GCK mutation mapping in exon 9 of the gene. Conclusions: We described a case of a patient misdiagnosed as T2DM. Only after the observation of a mild hyperglicemia also in his three sons, we supposed the diagnosis of MODY 2 and we confirmed it through the genetic test. These observations enforce the validity of the designed clinical algorithm for the identification of patients to be selected for the genetic diagnosis of MODY 2.
\end{abstract}

\section{Keywords}

MODY, Diabetes Mellitus, GCK, Glucokinase Gene

\section{Introduction}

Maturity-Onset Diabetes of the Young (MODY) is a clinically heterogeneous group of disorders characterized by autosomal dominantly inherited non-insulin dependent form of diabetes, classically presenting in adolescence or young adults before the age of 25 years [1].

MODY is the consequence of a genetic primary defect of pancreas beta-cells function derived from a combination of different mutations in at least six different genes [2] with a sub classification according to the gene involved. The most common clinical forms of MODY are type 1 and 3, due respectively to mutations of Hepatocyte nuclear 
factor (HFN) 4 alpha and 1 alpha, and MODY 2, caused by mutations of glycolytic enzyme glucokinase GCK genes [3].

MODY 2 is characterized by a mild chronic fasting hyperglicemia stable by aging and a very low risk for the chronic microvascular complications, probably similar to that in the general population [4]. Indeed, only few reports, regarding the development of the chronic microvascular complications in patients with GCK-diabetes, have been published [5]. Patients usually do not require pharmacological treatment [6].

GCK-MODY is often under-diagnosed because it is usually asymptomatic and benign and many cases are misclassified as type 1 or type 2 diabetes or impaired fasting glucose [7].

It is very important to correctly identify GCK-MODY because its treatment, follow-up, and prognosis are different from the other forms of diabetes. Genetic testing represents the gold standard to correctly identify MODY diabetes but it is expensive and only available in specialized laboratories so that various algorithms have been proposed that include several clinical and laboratory observations in order to select patients to be submitted to the molecular analysis [8].

We report the case of three brothers affected by fasting hyperglicemia, in which the genetic analysis is determined to confirm the suspected diagnosis of MODY2 and to reveal the presence of the same disease in their father, previously misdiagnosed as T2DM.

\section{Patients}

Three brothers of 25, 24 and 13 years old, respectively, were addressed to our Endocrine Unit because of fasting hyperglicemia.

History revealed that their father was diagnosed as affected from Type 2 diabetes.

At the time of the observation, there were no symptoms as polyuria, polydipsia, weight loss and ketoacidosis usually suspicious of Type 1 diabetes diagnosis [9]. All the patients and their father showed similar clinical and metabolic features: the similar BMI values, $18,20,19,21 \mathrm{~kg} / \mathrm{m}^{2}$ respectively; fasting plasma glucose under $132 \mathrm{mg} / \mathrm{dl}$; the HbAlc and the C-peptide were in the normal range; the HOMA-IR was normal; the glycosuria and ketonuria were absent.

Anti-beta cells antibodies as GAD (Glutamic Acid Decarboxylase), IAA (Insulin Autoantibodies) and ICA (Islet cell antibodies) were absent in all brothers. No signs of metabolic syndrome were present. All the patients showed a glyceamic profile slightly abnormal (see Table 1). They were treated with diet alone or sulphanilurea tablets.

All the above-mentioned characteristics were presents also in their father, so we hypothesized a family-based disease, specifically a MODY 2.

For these observations all the patients were submitted to genetic analysis.

\section{Materials and Methods}

After written informed consent, genomic DNA was extracted from the peripheral blood sample of each patient by using QIAmp-Blood MINI Kit (Qiagen, Valencia, CA, USA).

Polymerase chain reaction (PCR) amplifications for all the 10 GCK coding regions, 
Table 1. Clinical and biochemical features of patients.

\begin{tabular}{ccccc}
\hline Relation & Father & Brother 1 & Brother 2 & Brother 3 \\
\hline Gender M/F & M & M & M & M \\
Age at the first diagnosis (years) & 31 & 25 & 24 & 14 \\
BMI (kg/m $\left.{ }^{2}\right)$ & 21 & 18 & 20 & 19 \\
Fasting plasma glucose (mg/dl) & 129 & 128 & 132 & 131 \\
HbAlc (mmol/mol) & 47 & 45 & 50 & 48 \\
C-peptide (ng/dl) & 2.2 & 1.8 & 1.7 & 2.1 \\
HOMA-IR & Normal & Normal & Normal & Normal \\
Glycosuria (mg/dl) & Absent & Absent & Absent & Absent \\
Ketonuria (md/dl) & Absent & Absent & Absent & \\
Anti-beta cells antibodies (GAD, ICA, IAA) & Absent & Absent & Absent & Absent \\
\hline
\end{tabular}

including the exon-intron boundaries were performed in a $50 \mu \mathrm{L}$ volume containing 1.5 $\mathrm{mM} \mathrm{MgCl}$ (Thermo Fisher Scientific), 1× PCR Gold Buffer (Thermo Fisher Scientific), $0.25 \mathrm{mM}$ dNTPs, $10 \mathrm{pmol}$ of primers, $1.25 \mathrm{U}$ of AmpliTaq Gold DNA polymerase (Thermo Fisher Scientific), and 100 ng of genomic DNA. PCR conditions and the sets of primers used have been described elsewhere (Tinto N et al. 2008 [10] with some modifications in the following primers: exon3

Fw 5'-TAATATCCGGGCTCAGTCACC-3' and

Rv 5'-CTGAGATCCTGCATGGCCTTG -3';

exon $10 \mathrm{Fw}$ 5'-TCCTCTTCTCGTCCCCCTTC-3'.

Amplicons were purified with the NucleoSpin Gel and PCR Clean-up Kit (MachereyNagel GmbH \& Co. KG, Germany) and sequenced with the BigDye Terminator Cycle Sequencing Kit, version 3.1 (Thermo Fisher Scientific). After the purification with the NucleoSEQ Kit (Macherey-Nagel) the sequencing reactions were loaded onto an ABI $3130 \times 1$ Genetic Analyzer (Thermo Fisher Scientific) and data were analyzed with Sequencing Analysis software, version 5.3 (Thermo Fisher Scientific). We confirmed the mutations twice starting from the PCR step.

\section{Results}

Genetic analysis revealed the presence in all the analyzed family members of the nonsense Ser383X GCK mutation (codon change: TCG > TAG) mapping in exon 9 of the gene (see Figure 1). This mutation has been previously reported in the Human Gene Mutation Database [11].

\section{Discussion}

MODY is an infrequent disease (approximatively $1 \%-2 \%$ of all cases of diabetes) [12]. The precise prevalence depends on the type of MODY and on the criteria used to define affected status. 


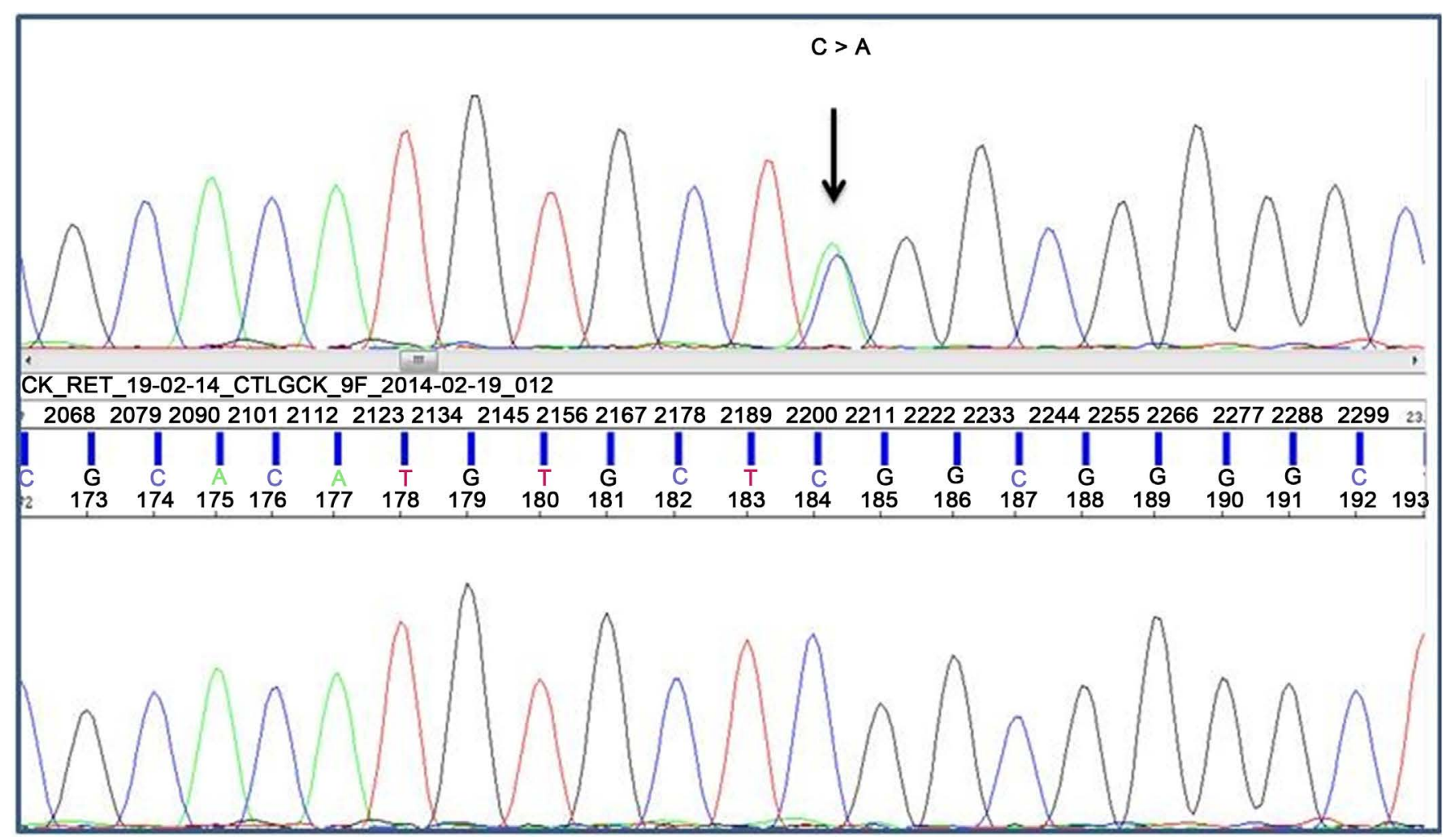

Figure 1. Top: Electropherogram of the GCK exon 9 sequence with the Ser383X mutation (TCG > TAG). The black arrow indicates the C to A transition in heterozygous state. Bottom: The same wild-type sequence in a control subject.

MODY includes a heterogeneous group of monogenic disorders that differ with regard to genetic, metabolic and clinical features. It is considered a rare variant of diabetes with mutations of both the Glucokinase (GCK) and Hepatocyte nuclear factor $1 \alpha$ (HNF1A) genes, accounting for up to $85 \%$ in Europe. It is frequently misdiagnosed as Type 1 or Type 2 diabetes, with an inappropriate therapy and follow-up in both cases [7] [13]. Therefore, a correct diagnosis of MODY is required and genetic analysis, with up to $100 \%$ sensitivity, represents the gold standard [14]. Unfortunately genetic testing is expensive and performed by only specialized laboratories.

In order to select the appropriate candidate to submit to the genetic analysis, several algorithms have been developed. For example Shields et al. [15] planed a model in which the age at diagnosis below 30 years and a family history of diabetes can move towards a differential diagnosis between MODY and T2DM and T1DM respectively [15], requiring mutational analysis to confirm the diagnosis.

MODY2 is caused by heterozygous mutations in glucokinase gene and is characterized by a metabolical compensated condition that exhibits as a mild form of non-progressive hyperglicemia, usually asymptomatic [16]. Generally, MODY 2 patients are adolescents or young adults with a normal weight and familial history of diabetes in two or three consecutive generations [17].

Here we report the case of three brothers that we suspected as affected by Type 1 diabetes because of their low BMI values, even if they didn't present any other clinical 
or biochemical parameters for this diagnosis. Their father, who was diagnosed as affected from Type 2 diabetes at the age 31 years old, had a low BMI value and feeble hyperglicemia, also. Because this criteria corresponded to the ones of the Shield's algorithm, we decided to perform the genetic analysis for MODY. In particular, considering the mild disease phenotype of the patients, we analyzed the GCK gene. In all the three brothers and in their father, we found the nonsense Ser383X mutation, confirming the suspected diagnosis of MODY 2. Interestingly, in this family we observed a highly phenotypic homogeneity.

\section{Conclusions}

We described a frequent case of a patient that was misdiagnosed as T2DM. Only after the observation of a mild hyperglicemia also in his three sons, we supposed the diagnosis of MODY and we confirmed it through the genetic test.

These observations enforce the validity of the designed clinical algorithm for the identification of patients to be selected for the genetic diagnosis of MODY, but at the same time, they suggest the need to perform a screening to unmask the presence of an asintomatic disease in the relatives of patients with only mild fasting hyperglicemia.

\section{Conflict of Interest}

All authors state that they have no conflicts of interest.

\section{References}

[1] Fajans, S., Bell, G.I. and Polonsky, K.S. (2001) Molecular Mechanism and Clinical Pathophysiology of Maturity-Onset Diabetes of the Young. The New England Journal of Medicine, 345, 971-980.

[2] Vaxillaire, M. and Froguel, P. (2008) Monogenic Diabetes in the Young, Pharmacogenetics and Relevance to Multifactorial Forms of Type 2 Diabetes. Endocrine Reviews, 29, 254264. http://dx.doi.org/10.1210/er.2007-0024

[3] Stanik, J., Kusekova, M., Huckova, M., et al. (2012) Impact of Type 2 Diabetes on Glucokinase Diabetes (GCK-MODY) Phenotype in a Roma Family-Case Report. Endocrine Regulations, 46, 99-105.

[4] Steele, et al. (2014) Prevalence of Vascular Complications among Patients with Glucokinase Mutations and Prolonged, Mild Hyperglicemia. JAMA, 311, 279-286.

[5] Giuffrida, F.M. and Reis, A.F. (2004) Genetic and Clinical Characteristics of Maturity-Onset Diabetes of the Young. Diabetes, Obesity and Metabolism, 7, 318-326. http://dx.doi.org/10.1111/j.1463-1326.2004.00399.x

[6] Stride, et al. (2014) Cross-Sectional and Longitudinal Studies Suggest Pharmacological Treatment Used in Patients with Glucokinase Mutations Does Not Alter Glycaemia. Diabetologia, 57, 54-56.

[7] Anik, A., Catli, G., Abaci, A. and Bober, E. (2015) Maturity-Onset Diabetes of the Young (MODY): An Update. Journal of Pediatric Endocrinology and Metabolism, 28, 251-263.

[8] Kavvoura, F.K. and Owen, K.R. (2013) Maturity Onset Diabetes of the Young: Clinical Characteristics, Diagnosis and Management. Pediatric Endocrinology Reviews, 10, 234-242.

[9] American Diabetes Association (2010) Diagnosis and Classification of Diabetes Mellitus. 
Diabetes Care, 33, S62-S69.

[10] Zagari, A., Capuano, M., De Simone, A., Capobianco, V., Daniele, G., Giugliano, M., Spadaro, R., Franzese, A. and Tinto, N. (2008) Glucokinase Gene Mutations: Structural and Genotype-Phenotype Analyses in MODY Children from South Italy. PLoS One, 3, e1870.

[11] Stenson, P.D., et al. (2014) The Human Gene Mutation Database: Building a Comprehensive Mutation Repository for Clinical and Molecular Genetics, Diagnostic Testing and Personalized Genomic Medicine. Human Genetics, 133, 1-9.

http://dx.doi.org/10.1007/s00439-013-1358-4

[12] Glovn, et al. (2009) Prevalence of GCK Mutations in Individuals Screened for Fasting Hyperglicemia. Diabetologia, 52, 172-174.

[13] Gaya Thanabalasingham, B.M., et al. (2012) Systematic Assessment of Etiology in Adults with a Clinical Diagnosis of Young-Onset Type 2 Diabetes Is a Successful Strategy for Identifying Maturity-Onset Diabetes of the Young. Diabetes Care, 35, 1206-1212. http://dx.doi.org/10.2337/dc11-1243

[14] Kim, S.-H. (2015) Maturity-Onset Diabetes of the Young: What Do Clinicians Need to Know? Diabetes \& Metabolism Journal, 39, 468-477. http://dx.doi.org/10.4093/dmj.2015.39.6.468

[15] Shields, B.M., McDonald, T.J., Ellard, S., Campbell, M.J., Hyde, C. and Hattersley, A.T. (2012) The Development and Validation of a Clinical Prediction Model to Determine the Probability of MODY in Patients with Young-Onset Diabetes. Diabetologia, 55, 1265-1272. http://dx.doi.org/10.1007/s00125-011-2418-8

[16] McDonald, T.J. and Ellard, S. (2013) Maturity Onset Diabetes of the Young: Identification and Diagnosis. Annals of Clinical Biochemistry, Pt5, 403-415.

[17] Spégel, P., Ekholm, E., Tuomi, T., et al. (2013) Metabolite Profiling Reveals Normal Metablic Control in Carriers of Mutations in the Glucokinase Gene (MODY2). Diabetes, 62, 653661.

Submit or recommend next manuscript to SCIRP and we will provide best service for you:

Accepting pre-submission inquiries through Email, Facebook, LinkedIn, Twitter, etc.

A wide selection of journals (inclusive of 9 subjects, more than 200 journals)

Providing 24-hour high-quality service

User-friendly online submission system

Fair and swift peer-review system

Efficient typesetting and proofreading procedure

Display of the result of downloads and visits, as well as the number of cited articles

Maximum dissemination of your research work

Submit your manuscript at: http://papersubmission.scirp.org/

Or contact jdm@scirp.org 